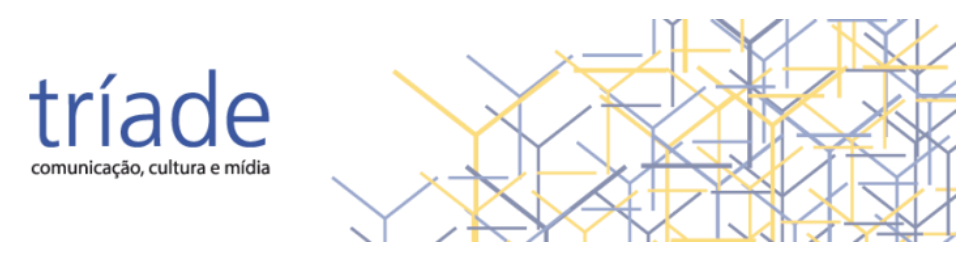

\title{
O anonimato online como ponte entre experiências cotidianas e presença digital na performance identitária
}

\author{
Online anonimity linking everyday experiences and digital presence on identity \\ performance
}

El anonimato online como puente entre experiencias cotidianas y presencia digital en el performance de identidades

Elisa Beatriz Ramírez Hernández - Universidade Federal de Minas Gerais | Belo Horizonte | Minas Gerais | Brasil | elisabeatriz88@gmail.com |

(D) https://orcid.org/0000-0001-8704-2227.

Angela Cristina Salgueiro Marques - Universidade Federal de Minas Gerais | Belo Horizonte | Minas Gerais | Brasil | angelasalgueiro@gmail.com |

(D) https://orcid.org/0000-0002-2253-0374.

Resumo: O artigo aborda a dimensão política nas apropriações do recurso do anonimato online, a partir de uma análise de conversações sobre migração no site cubano Cubadebate, entre 2013 e 2017. Explora-se a perspectiva das affordances da plataforma e as possibilidades expressivas desse recurso, a fim de argumentar a pertinência de abordagens que considerem a relevância do contexto comunicativo e político dessas práticas. O modelo de análise de conversações online complementa-se com entrevistas a jornalistas e diretores do meio, a partir de três eixos metodológicos que se entrelaçam: a dimensão textual dos comentários, a prática discursiva no ambiente digital e as características do contexto social mais amplo que rodeia essas interações. A pesquisa identifica três apropriações principais do anonimato que evidenciam essa prática comunicativa como uma construção identitária que vincula a experiência cotidiana dos cubanos e sua presença online.

Palavras-chave: Anonimato. Conversações Online. Affordances. Identidades digitais. Cuba.

Abstract: The article explores the political dimension related using of online anonymity, based on an analysis of conversations about migration issues on the Cuban site Cubadebate, between 2013 and 2017. It explores the perspective of the platform's affordances and the expressive possibilities of this resource, in order to argue the relevance of approaches that consider the communicative and political context as a key aspect of these practices. The analysis model of online conversations is complemented by interviews with journalists and directors of Cubadebate, based on three intertwined methodological axes: the textual dimension of the comments, the discursive practice in the digital environment and the characteristics of the wider social context that surrounds these interactions. The research identifies three main appropriations of anonymity that highlight this practice as an 
identity construction that links Cubans' everyday experience with their online presence.

Keywords: Anonimity. Online conversations. Affordances. Digital identities. Cuba.

Resumen: El artículo aborda la dimensión política en las apropriaciones del recurso de anonimato online, basado en un análisis de conversaciones sobre migración en el sitio cubano Cubadebate, entre 2013 y 2017. Se explora la perspectiva de los affordances de la plataforma y las posibilidades expresivas de este recurso, a fin de argumentar la relevancia de los enfoques que consideran el contexto comunicativo y político como un aspecto esencial de esas prácticas. El modelo de análisis de conversación online se complementa con entrevistas con periodistas y directores de medios, basadas en tres ejes metodológicos entrelazados: la dimensión textual de los comentarios, la práctica discursiva en el entorno digital y las características del contexto social más amplio que rodea esas interacciones. La investigación identifica tres apropiaciones principales del anonimato que destacan esta práctica como una construcción de identidades que vincula la experiencia cotidiana de los cubanos y su presencia en línea.

Palabras clave: Anonimato. Conversaciones Online. Affordances. Identidades digitales. Cuba. 


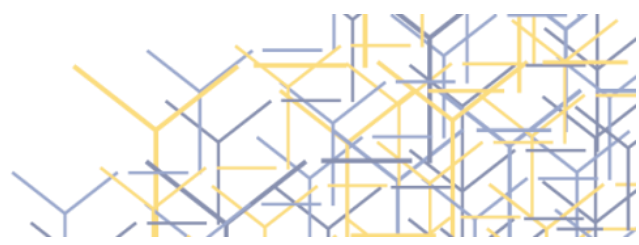

\section{Introdução}

Os condicionamentos históricos, econômicos e institucionais que conformam o sistema político cubano impactam também, de forma direta, na configuração de espaços públicos de comunicação na Ilha. A exigência de posicionamentos políticos radicais em favor do processo revolucionário; a metáfora da "praça sitiada" que não admite critérios dissidentes em um contexto de ameaças externas; a reprodução do capital simbólico socialista pela classe dirigente e a intervenção do Partido Comunista de Cuba (PCC) como regulador absoluto da vida social são alguns dos aspectos que caracterizam o sistema político e comunicativo cubano. Sob esse viés, a mídia é regulada diretamente pelo Departamento Ideológico do Comitê Central do PCC, atingindo também todas as instâncias do poder político no nível local. Nesse sentido, os meios de comunicação cubanos se consideram estatais em termos de propriedade e oficiais pela subordinação ao Governo, propósitos e conteúdo (HERRERA, 2016).

De acordo com Herrera (2016, p. 87)1', o processo de "sovietização" em Cuba derivou em um modelo verticalizado de tomada de decisões, centralizado na figura do Partido e seu líder Fidel Castro (assim como da classe histórica dirigente no poder), e legitimado pelo consenso de que a "direção da Revolução" encarnava a força e a vontade do poder popular (HERRERA, 2016, p. 84). Dessa forma, foi se consolidando um sistema de participação representada acima da participação direta, marcado pela adoção de procedimentos burocráticos nas estruturas políticas formais, o que tem afetado o protagonismo da cidadania na tomada de decisões sobre assuntos de caráter público (GUANCHE, 2015).

1 Seguindo Linz (1986), refere-se à forte influência da antiga União Soviética no desenvolvimento econômico e na implementação de políticas socialistas cubanas após o triunfo da Revolução. 
Assim, o sistema midiático faz parte apenas da paisagem mais ampla do espaço público cubano, onde convivem atualmente uma multiplicidade de esferas públicas e posições encontradas entre formas preestabelecidas e novos atores; o que impacta não apenas na produção de conteúdos midiáticos, mas na constituição do debate público. A esse respeito, Herrera (2016, p. 114 $)^{2}$ traça o seguinte mapa de esferas públicas em Cuba: a esfera pública política oficial; a esfera pública oficial e cultural/intelectual; a esfera pública oposicionista; e esferas públicas críticas oficialmente toleradas.

Nesse panorama, o espaço digital cubano vem se tornando cada vez mais amplo e diverso, sobretudo a partir do ano de 2015, já que o acesso à Internet em Cuba tem se estendido à população em salas institucionais de navegação e alguns ambientes domésticos "escolhidos", em espaços públicos de conexão wifi e mais recentemente em dispositivos móveis através da conexão 3G; mas ainda muito timidamente e sempre com preços extremamente altos se comparados com os salários dos trabalhadores comuns. Por outro lado, do número oficial de 4,5 milhões de usuários de Internet em Cuba desconhece-se os que acessam via instituições do governo, empresas ou contas individuais de conexão. Pode-se dizer que é insuficiente a caracterização do consumo de internet por variáveis sócio demográficas como idade, gênero, nível escolar, ou distribuição regional; tampouco se conhece a frequência de uso e outros indicadores que possam qualificar melhor o impacto desse serviço na vida cotidiana das pessoas (INTER PRESS SERVICE EN CUBA, 2018). Nesse sentido, os dados públicos sobre conectividade na Ilha, ainda que ilustrem um crescimento do acesso à rede no país, não exprimem as características da qualidade e quantidade de tempo do uso dessa conexão.

É preciso considerar também que o avanço da Internet em Cuba está marcado por um controle quase absoluto das telecomunicações pelo

\footnotetext{
${ }^{2}$ Com base em Bathrick (1995).
} 
governo, que se exprime em restrições de navegação ${ }^{3}$, pois são bloqueados muitos dos domínios de páginas estrangeiras, redes sociais e sites informativos considerados "subversivos" pelas autoridades da Ilha. Por outro lado, existe no país apenas uma um monopólio das comunicações nacionais, a Empresa de Telecomunicaciones de Cuba S.A. (ETECSA) que, mesmo com uma parte de capital estrangeiro, responde também às diretrizes do governo. Assim, a expansão (gradual e controlada) desse serviço em Cuba começou em espaços institucionais como universidades, centros de investigação, empresas estatais, meios massivos de comunicação, dentre outros.

Por outra parte, o portal de notícias Cubadebate tem alcançado uma posição privilegiada no panorama online das últimas décadas na Ilha, ao incorporar tanto as diretrizes políticas governamentais quanto as particularidades de algumas zonas de conflito da realidade nacional. Cubadebate, criado em 2003, é o meio mais visível da web cubana, site de referência mundial sobre temas de Cuba e o site informativo melhor posicionado no âmbito nacional, um dos primeiros sites de acesso no país, superado apenas por Google e as redes sociais ${ }^{4}$. Muitos são os fatores que ao longo de quinze anos convergiram na evolução dessa plataforma, fundamentalmente a abertura ao debate público sobre temas de atualidade através do espaço de comentários (após a incorporação à Web 2.0 em 2009).

Neste artigo apresentamos alguns resultados de uma pesquisa que aborda processos de politização em conversações sobre migração no fórum de comentários do site Cubadebate, de 2013 a 2017. O marco temporal escolhido delimita um período relevante no processo de transformações sociopolíticas que acontecem recentemente em Cuba: duas mudanças no

\footnotetext{
${ }^{3}$ A Resolução 127/2007 do Ministério da Informática y as Comunicações sobre seguridade informática (Disponível em: https://goo.gl/WTGzlY.) declara como ilícita a utilização de canais institucionais de acesso à Internet para expressar opiniões privadas.

${ }^{4}$ Segundo o site Alexa: https://www.alexa.com/siteinfo/cubadebate.cu.
} 
governo da Ilha depois de Fidel Castro (Raúl Castro (2006) e Miguel Diaz Canel (2018)), marcadas pelo desenvolvimento de medidas econômicas e sociais e um processo de reforma constitucional (2018); a emergência de um novo panorama migratório a partir de leis cubanas que flexibilizaram o fluxo de pessoas através da fronteira (2013 e 2018), assim como o fim da política americana que privilegiava a imigração ilegal cubana nos Estados Unidos (2017); e a recente popularização do acesso à internet em Cuba5 (2015).

A presença da temática migratória nas conversações, por outro lado, atravessa o imaginário do período revolucionário e envolve situações dissensuais, escolhas individuais/familiares e condicionamentos sociais. Assim, enfatizamos na análise de conversações que tiveram lugar em momentos significativos relacionados à migração cubana e que estimularam ampla participação no fórum de Cubadebate e no espaço público nacional de forma geral. A sucessão de vários momentos de êxodo migratório cubano após a Revolução de 1959, fundamentalmente para os Estados Unidos da América (EUA), tem gerado uma diáspora equivalente a $10 \%$ da população da Ilha e outorgou à migração o status de "traição à Pátria" para o governo cubano. Contudo, em meio às mudanças geracionais no próprio processo revolucionário, o que era considerado inicialmente apenas como um exílio político anti-Castro e pró-americano foi se assumindo como parte das dinâmicas migratórias atuais (AJA et al., 2017).

A pesquisa que dá origem a este artigo abrange a análise de 28 conversações (mais de quatro mil comentários postados no total), a partir de três eixos de análise que atravessam esse espaço conversacional: a) a (U) dimensão do texto (análise qualitativo de conteúdo das mensagens e fios de discussão dispostos e armazenados no fórum online); b) a dimensão da prática discursiva (análise crítica do ambiente online no qual essas

\footnotetext{
${ }^{5}$ A quantidade de usuários de internet em Cuba aumentou de 27\%, em 2014, para 40\% em 2016 (OFICINA NACIONAL DE ESTADÍSTICA E INFORMACIÓN, 2017, p. 7).
} 
mensagens são produzidas e consumidas); e c) a dimensão da prática social (avaliação da rede mais ampla de relações sociais à qual o conteúdo das mensagens e a troca comunicativa se relacionam), (WITSCHGE, 2008). A partir dessas dimensões, observamos como as marcas do anonimato no fórum são articuladas com as estratégias de apropriação criativa da plataforma pelos sujeitos em interação, assim como com as dimensões políticas desse espaço conversacional. Com esse objetivo, buscamos identificar quais apropriações do anonimato pelos interlocutores identificam o uso desse recurso em ambientes tecnodiscursivos como um gesto político de presença online.

Por outra parte, as entrevistas realizadas com diretores e jornalistas/editores de Cubadebate $^{6}$ contribuíram para a compreensão das dinâmicas comunicativas do fórum, ao evidenciarmos os entrelaçamentos entre aspectos da arquitetura discursiva, as marcas do contexto em que se desenvolvem essas trocas e a atuação performativa dos interlocutores. No contexto de restrições à expressão pública e das constantes transformações que vivencia a sociedade cubana atual, consideramos que as novas possibilidades de interação online e os usos do recurso do anonimato nessas plataformas são questões que podem trazer luz aos estudos sobre comunicação online e suas interfaces com transformações políticas. Sobretudo, no que diz respeito à construção de uma perspectiva capaz de ultrapassar visadas deterministas e propor uma abordagem crítica do impacto das TIC em relação com as especificidades e características do contexto sociopolítico e comunicacional em que se inserem os fenômenos analisados.

O artigo apresenta alguns aportes de estudos sobre usos do anonimato online sob a perspectiva das affordances e aponta necessidade de se considerar essas apropriações na relação com o contexto político e

\footnotetext{
${ }^{6}$ Entre fevereiro e março de 2018 foram realizadas cinco entrevistas presencias, de tipo semi-estruturada, a diretores e jornalistas do meio.
} 
comunicativo em que se inserem. Por fim, a pesquisa aponta três dinâmicas de uso do anonimato no fórum estudado que se revelam como base para o encadeamento de interações, para enquadramentos e para construções identitárias. Dessa forma, o anonimato é considerado como uma forma de presença online que revela traços da experiência cotidiana online dos sujeitos e sua constituição relacional como interlocutores.

\section{Abordagem do anonimato online sob a perspectiva das affordances}

De forma geral, estudos que incorporam a mediação digital nas interações humanas se interessam em explorar as relações entre o "mundo real" e o "mundo virtual", mas destacamos aqui as perspectivas que defendem a intervenção da tecnologia para além de sua função como facilitadora ou como extensão da vida social. Assim, assumimos que o entorno online faz parte de um contexto sociocultural e político-econômico maior, moldado por circunstâncias históricas, de forma que plataformas virtuais e práticas sociais se constituem mutuamente na dinâmica diária de sociabilidade e criatividade das pessoas (VAN DIJCK, 2013).

O desenvolvimento de redes sociais populares como Facebook e Twitter têm estimulado pesquisas sobre as possibilidades e constrangimentos impostos pelas diferentes plataformas (MAIA; REZENDE, 2016). Entretanto, menos atenção é dada aos estudos sobre fóruns de comentários nos meios massivos digitais, apesar de que esses espaços (comments field) são considerados como uma das formas mais populares

(Uل de plataformas UGC (User Generated Content) na mídia (GRAHAM; WRIGHT, 2015). Embora a plataforma discursiva que analisamos nesta pesquisa seja o fórum de comentários do site de notícias Cubadebate, acreditamos que o nosso enfoque difere em alguma medida da visão predominante em estudos similares. 
Dentre as pesquisas que abordam os comentários produzidos em espaços interacionais da internet, predominam aquelas que investem na análise de padrões de civilidade e incivilidade (READER, 2012; COE; KENSKY; RAINS, 2014); o estudo da interatividade e características formais desses espaços e sua contribuição para a produção/circulação de conteúdo online (BUENO, 2015); assim como abordagens sobre a qualidade deliberativa dessas trocas (SAMPAIO; BARROS, 2012). Ao que parece, as pesquisas mostram que esses espaços são considerados ora como uma plataforma interacional similar a outros âmbitos discursivos na web, ora em relação à sua contribuição para a prática jornalística no meio em que se inserem.

Recentemente, perspectivas metodológicas que abordam dinâmicas comunicacionais e sociais no ambiente online, os chamados "métodos digitais", destacam a necessidade de se compreender o funcionamento dos dispositivos online e de se fundamentar as pesquisas nos dados coletados (ROGERS, 2016 apud D'ANDRÉA, 2018). Nesse viés, o desenvolvimento dos estudos de plataformas (platform studies) incorpora uma concepção desses ambientes como arquiteturas na quais são modeladas dinâmicas de sociabilidade; como as plataformas pré-condicionam, sugerem ou constrangem diversos usos através de determinadas funções, o que diz respeito às affordances (D'ANDRÉA, 2018; WELTEVREDE; BORRA, 2016). Esse é um termo multivalente e pode ser considerado como um conceito chave para abordar as interfaces de mídias sociais e as relações que se estabelecem entre a tecnologia e seus usuários (BUCHER; HELMOND, 2017).

Sob essa perspectiva, algumas abordagens recentes sobre discussões políticas online que consideram relevante a mediação tecnológica costumam focar apenas em algum aspecto dessas affordances. Particularmente, tem chamado a atenção dos pesquisadores elementos como o anonimato (WRIGHT; STREET, 2007); o caráter assíncrono da conversação (FREELON, 2010); a prática de moderação dos fóruns 
(WRIGHT, 2009) e as características da rede quanto à exposição de pontos de vista diferentes ou similares (homophily, like minded) (MAIA; REZENDE, 2016), dentre outras configurações. Contudo, esses estudos nem sempre conseguem mostrar a diversidade e complexidade das trocas comunicacionais que atravessam as esferas públicas online como espaços diferenciados de interação.

A correlação entre a participação anônima de sujeitos em ambientes conversacionais da internet e uma maior presença de incivilidade e desrespeito entre os interlocutores (flaming) ganha a atenção de pesquisas sobre diferentes tipos de plataformas como redes sociais e fóruns de comentários em sites de notícias. Evidências de estudos empíricos tendem a confirmar que $o$ anonimato estimula a proliferação de ataques pessoais nesses espaços virtuais (MUNGEAM; CRANDALL, 2011; MAIA; REZENDE, 2016). Essa perspectiva reforça um interesse generalizado entre os pesquisadores por analisar como as affordances das plataformas impactam na qualidade dos discursos e em processos de deliberação online.

Conforme salientam Weltevrede e Borra (2016), por outro lado, o foco nas affordances poderia se restringir a pouco mais do que uma descrição das propriedades materiais dos dispositivos. Por esse motivo, outras terminologias mais abrangentes se referem a "imagined affordances" (possibilidades imaginadas) para descrever interações que "emergem entre as percepções dos usuários, as intenções dos designers e a materialidade das tecnologias" (WELTEVREDE; BORRA, 2016, p. 1). Nesse sentido, a noção de device cultures (culturas do dispositivo) busca precisamente definir esses processos de negociação.

As culturas de dispositivo podem ser definidas como a interação entre os usuários e a plataforma; como a atividade é imaginada, curada e prescrita na arquitetura da plataforma; como as affordances são ativadas pelos usos e práticas (não) previstos que ocorrem nas plataformas e no interior delas; e como os dados são coletados e processados pelas 
plataformas. (WELTEVREDE; BORRA, 2016, p. 2, tradução nossa).

Essa proposta nos parece relevante para analisarmos a dimensão política de conversações online, levando em consideração o nosso objetivo de incorporar a análise da configuração da plataforma como um dos eixos metodológicos fundamentais a serem observados. Nesse viés, nos referimos a processos de politização que podem emergir no cerne de um processo discursivo em que regras, identidades e lugares sociais preestabelecidos são reconfigurados pelos sujeitos que conversam no ambiente virtual. Assim, essa dinâmica deve ser compreendida também a partir da tensão entre as affordances que caracterizam a plataforma e esse ato de "imaginar" outros lugares e vozes possíveis que não foram previamente programadas pelos algoritmos e as lógicas binárias do digital.

Por outra parte, a nossa análise das conversações em Cubadebate difere em alguma medida dos estudos que associam o anonimato à privacidade, afastamento ou solidão dos sujeitos, ou bem ligado a comportamentos ofensivos que reduzem a qualidade de discussões online. Nesse sentido, e importante destacar que existem conversações, por exemplo, que perpassam tentativas, disputas de sentido e explorações enunciativas que ultrapassam a ordem vigente. Assim, novas possibilidades performativas emergem nas redes sociais online, criando lugares discursivos a partir não só das argumentações possíveis, mas do desdobramento emocional que se configura na interação.

Assim, seguimos a perspectiva de Asenbaum (2018, p. 1), ao definir que: "o anonimato é uma performance da identidade dependente do contexto que expressa sentimentos privados na esfera pública ao negar alguns aspectos da personalidade legalmente identificada e/ou fisicamente incorporada". O autor afirma ainda que os efeitos do anonimato são ao mesmo tempo positivos e negativos, e destaca o carácter contraditório e dialético dessa condição na esfera pública que, diferentemente do âmbito 
privado, se torna uma pré-condição para a emergência do anônimo. Assim, ele argumenta, como vimos, que o anonimato apenas protege a identidade enquanto está se comunicando um conteúdo publicamente, de forma que "facilita uma forma privada de engajamento na arena pública discursiva" (ASENBAUM, 2018, p. 11).

\section{Dimensões políticas nas apropriações do anonimato online}

São vários os fatores que influenciaram o crescente protagonismo do fórum de comentários de Cubadebate no espaço público nacional. Além do trabalho de posicionamento e aprimoramento das formas de comunicação digital no site, a articulação com outras arenas institucionais e midiáticas do país, assim como o incremento do acesso à internet em Cuba, possibilitaram a presença dos cubanos no site. Por mais que Cubadebate tenha surgido com uma projeção marcadamente internacional, a evolução interativa do meio levou a uma maior demanda interna pelo tratamento e discussão de temas sensíveis para a realidade do país. Contudo, é preciso aclarar que essa grande participação de leitores nos debates do meio não significa diretamente um acesso da ampla maioria da população a esse espaço discursivo, uma vez que o consumo de internet em Cuba é ainda muito limitado e se faz necessário um estudo aprofundado dos novos usos do serviço de conexão à rede.

Do ponto de vista editorial, um posicionamento efetivo do projeto político cubano na internet, objetivo inicial de Cubadebate, implicava adotar a diversidade que caracteriza o espaço online e consequentemente adotar uma política de moderação mais aberta do que outros meios governistas na Ilha. Já sob a perspectiva dos interlocutores, a possibilidade do anonimato no fórum poderia também atuar na flexibilidade dos limites da liberdade de expressão nesse espaço. É preciso destacar também que, de forma estrutural, Cubadebate não integra diretamente o organograma do sistema midiático do país. O fato desse espaço estiver atrelado a uma instância mais 
próxima da máxima direção do governo, com o envolvimento do próprio Fidel Castro, pudesse ter influenciado de alguma forma a condução de uma política editorial diferenciada e assim o seu impacto no país.

De acordo com os editores do site, regras de moderação são seguidas para evitar ofensas de todo tipo (de uns usuários a outros ou contra os líderes e as ideias do governo, etc.), embora declarem que uma média de $85 \%$ dos comentários dos leitores enviados à plataforma são aprovados para publicar (CONCEPÇÃO7, 2018 , informação verbal). Contudo, o certo é que também "a aprovação dos comentários passa pela subjetividade do editor de plantão" (FIGUEREDO8, 2018, informação verbal).

Para participar no fórum de Cubadebate, os indivíduos devem indicar um nome ou nickname e um e-mail que não requer ser confirmado, de forma que o caráter anônimo da plataforma possibilita a livre escolha na identificação dos participantes da conversação e impacta também na construção discursiva das interações. Nesse sentido, Berg (2016) destaca que os efeitos sociais do anonimato podem ser ambíguos e sua influência no comportamento humano depende principalmente do contexto. Se, por um lado, essa condição pode contribuir para os sujeitos se sentirem mais livres de julgamentos alheios na hora de atuar em público; isso também poderia conduzir a uma falta de civilidade nas discussões online, talvez porque os participantes se sentem menos responsáveis por suas palavras, argumenta o autor.

Por outro lado, Reader (2012, p. 507) aponta que, longe de se debater apenas se o discurso anônimo é uma causa ou um sintoma de incivilidade, "estudos adicionais devem focar menos no que pode causar o anonimato e mais em porque os comentaristas o usam". Nesse viés, analisamos as diferentes apropriações que os leitores fazem do recurso do anonimato no

\footnotetext{
${ }^{7}$ Relato de José Raúl Concepción: formado em Jornalismo pela Universidad de La Habana (UH) e atual Sub-director de Cubadebate.

8 Relato de Oscar Figueredo: formado em Jornalismo pela UH, jornalista/editor de Cubadebate.
} 
fórum e como isso é articulado com os pontos de vista expressados. Podemos encontrar, por exemplo, nicknames com o nome completo e dois sobrenomes da pessoa, ou com uma infinidade de possibilidades expressivas que são construídas na interação e que revelam diversas articulações entre o sujeito, sua fala e o contexto sociopolítico e comunicativo mais amplo.

\subsection{Usos do anonimato: experiência cotidiana e presença online}

Os resultados desta pesquisa evidenciam a existência de ao menos três formas de usos generalizados do recurso do anonimato no fórum estudado: 1) como recurso interacional, às vezes com fins de desqualificação do discurso do outro; 2) como síntese do enquadramento que relaciona o interlocutor com seu enunciado; e 3 ) como forma de construção identitária que busca legitimar a participação e critérios apresentados pelos sujeitos no espaço online. Nesta seção, abordamos essas dimensões a partir das particularidades e desdobramentos que mostram alguns exemplos mobilizados, a fim de mostrar como os lugares enunciativos construídos a partir desse recurso configuram dinâmicas interacionais específicas da presença online dos sujeitos interlocutores.

1) Recurso interacional, ainda com fins de desqualificação dos parceiros. De acordo com Berg (2016), o anonimato, pode ter efeitos positivos no discurso, uma vez que permite direcionar o foco da discussão para o que está sendo comunicado mais do que para o sujeito que fala. Contudo, a nossa análise revela que essa configuração online não exime os interlocutores de tentarem atrelar argumentos alheios às particularidades dos indivíduos com os quais interagem. Quando não são percebidas como suficientes as razões fornecidas pelos parceiros de interação, ou simplesmente há um desacordo com posicionamentos considerados às vezes radicais ou 


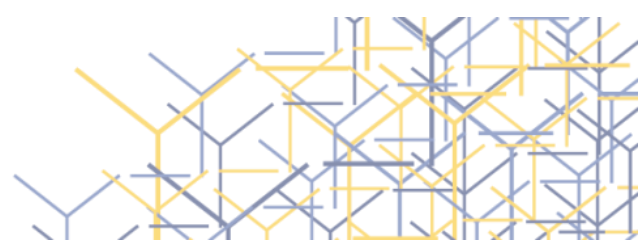

polêmicos, parece surgir a necessidade de se desvendar traços da identidade do outro. Assim, identificamos que os interlocutores podem se apropriar desse recurso discursivo para estabelecer vínculos com os parceiros de interação que, se bem poderiam orientar ações interacionais, tende a ser acionado para se desqualificar moralmente o outro (Fig. 1 e 2).

Figura 1 - Reapropriação dos pseudônimos empregados ${ }^{9}$

Jrvalor dijo:

Todo en la vida humana tiene un por que? Que desgracia para los familiares de Mayelin y me sumo al luto eterno de estos padres por la hija ausente. Pero me pregunto por que esta muchacha dejo a un lado su fobia marina y se tiro al estrecho peligroso

15 MARZO 2017 A LAS 22:20 / RESPONDERh

Tomás H. Vidal Cordero dijo:

jcovarde. Qué cínico eres.... respeta el dolor del padre, nadie mejor que él lo sabe y lo expuso en el comentario

16 MARZO 2017 A LAS 8:26 / RESPONDERT

Fonte: Captura de tela da conversação no fórum (realizada em novembro de 2018).

9 Comentário da conversação sobre a matéria "MINSAP reitera normativa sobre profesionales que abandonen sus misiones", publicada no site, em 3 de fevereiro de 2017. 


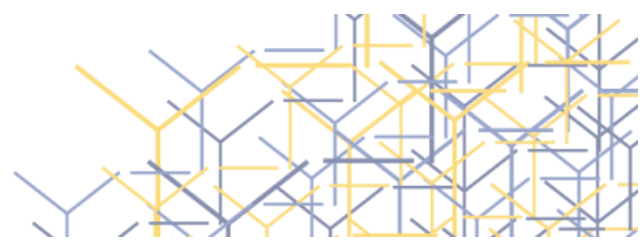

Figura 2 - Interação baseada em nomes dos interlocutores ${ }^{10}$

Wisleidys dijo:

No ha sido posible porque, nosotros los cubanos a pesar de vivimos en un pais tropical, no nos gusta trabajar la tierra, si se produejra mas en al parte agricola ahi si es verdad que se cumplirian las palabras de nuestro comandante

Viva Cuba.

\title{
8 NOVIEMBRE 2017 A LAS 15:21
}

\begin{abstract}
Carlos Gutiérrez dijo:
Wisleidys: Por tu nombre y por lo que dices, me parece que eres una persona muy joven. Yo ya no lo soy; Tengo 62 años, por lo que prácticamente naci con la Revolución. Llevo 42 años trabajando en la misma empresa estatal y he sido participante activo de todas las tareas politicas, sociales, militares y laborales que en cada momento han surgido, incluyendo largas movilizaciones en la agricultura, que eran muy frecuentes hasta hace poco.
\end{abstract}

Fonte: Captura de tela da conversação no fórum (realizada em novembro de 2018).

A conversação da Figura 1 mostra como o apelido utilizado pelo usuário @Jrvalor é transformado pelo parceiro de interação que o interpela como "jcovarde"11 para criticar seu posicionamento; enquanto na trocas da Figura 2, o usuário @Carlos Gutiérrez argumenta que a opinião expressada por@Wisleidys poderia estar baseada em um desconhecimento da história da Revolução, ao assumir que um nome assim corresponderia a uma pessoa mais nova.

2) Síntese de enquadramentos, sujeito e fala na voz dos interlocutores. Em uma conversação sobre a reforma migratória cubana de 2013, por exemplo, o nome do usuário @COSTO PASAPORTE indica já que o comentário trata do assunto dos altos

10 Comentário da conversação sobre a matéria "Estados Unidos anuncia nuevas restricciones para los viajes y el comercio con Cuba", publicada no site, em 8 de novembro de 2017.

${ }^{11}$ Sinalizamos que a grafia correta da palavra em espanhol é "cobarde" (com "b"), que, neste caso, é usada como antônimo de "valor" (coragem). 
custos do passaporte cubano, uma reclamação muito comum nos debates sobre migração no fórum. Da mesma forma, o nickname @SOLUCION FACIL resume ponta o posicionamento do interlocutor sobre a situação de crise migratória de cubanos na América Central que teve lugar em novembro de 2015. Ao discutirem sobre as restrições migratórias impostas pelo governo aos médicos cubanos (finais de 2015), o nome @Eso mismo digo yo é usado para expressar concordância com outro critério; os nomes @me gustaría una respuesta e @Una pregunta são empregados na busca por explicações e informações esclarecedoras; enquanto os usuários $@ m e$ sumo e @admiradora apoiam tanto ao meio Cubadebate pela publicação quanto ao Ministério de Saúde de Cuba.

Contudo, é difícil determinar se o nome é ligado unicamente àquele comentário específico, ou se trata do nickname assumido por esse interlocutor em todas suas participações no fórum, uma vez que os editores do site confirmam que os comentaristas usam geralmente os mesmos apelidos (ZAMORA ${ }^{12}$, 2018, informação verbal). Alonso ${ }^{13}$ (2018, informação verbal) e Zamora (2018, informação verbal) enfatizam a atitude de "fidelidade" dos comentaristas que participam no fórum do meio, talvez porque na esfera pública cubana (oficial), como afirma Figueredo (2018, informação verbal), "faltam espaços para as pessoas expressarem suas opiniões".

3) Construção identitária que visa legitimação de premissas defendidas e definição de lugares enunciativos. Nesse sentido, podemos perceber que há uma relação entre a construção de identidades discursivas e usos do anonimato do fórum, a qual

12 Relato de Oliver Zamora: jornalista da televisão cubana especializado em política internacional e editor em Cubadebate há quase uma década.

${ }^{13}$ Relato de Randy Alonso: fundador y attual director de Cubadebate. 
desdobra-se a partir de apropriações específicas, tais como: a) a utilização do mesmo nickname por alguns comentaristas assíduos no fórum; b) a explicitação de traços identitários o de identificação que permitem aos interlocutores legitimar pontos de vista apresentados a partir do seu lugar de fala ou descrever atitudes diante de uma assunto discutido; e c) a ressignificação de uma identidade nacional coletiva, geograficamente dispersa e afetivamente comum, que tensiona a definição unívoca do "cubano" como uma identidade política fixa em favor do governo e a Revolução.

De acordo com Asenbaum (2018), o anonimato não pode ser tomado como o oposto da identidade, mas como uma pré-condição para criar identidade em um processo comunicativo público, configurado por dimensões discursivas e pela agência dos interlocutores. $O$ autor se referese a três dimensões comunicativas afetariam o anonimato: a materialidade da infraestrutura ou da arquitetura discursiva do ambiente digital; a posição do interlocutor em estruturas de poder estabelecidas e a configuração de um conhecimento de sua identidade (o que se dá a ver através do uso de pseudônimos, marcadores e pistas como gênero, raça e idade, trabalho que realiza etc.). Assim, o anonimato é um processo inerentemente comunicativo (criar identidades negociadas publicamente) e não um estado marcado pela invisibilidade, não-detecção e não identificação.

De fato, constatamos a presença reiterada de interlocutores que mantêm os mesmos nomes em conversações diferentes, como é o caso de @cadillac, @Manuel Mercado, @José R. Oro, dentre outros. Aliás, há comentários em que um interlocutor se refere a alguém como se o conhecesse de outras conversações do site, como podemos observar quando o usuário @cadillac se refere a outro interlocutor para confirmar se essa pessoa seria a mesma que o ofendeu no fórum em outro momento anterior (Fig. 3); assim como @La mexicana ao insinuar que conhece a @cadillac se referindo a outros espaços da web cubana (Fig. 4). 


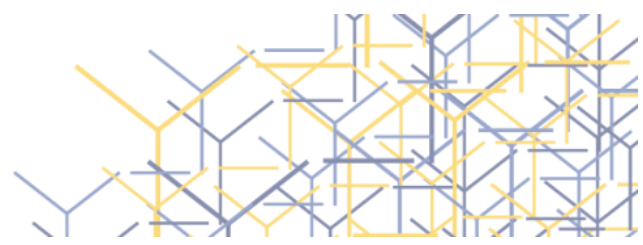

Figura 3 - Interlocutores do fórum se reconhecem pelos nomes empregados ${ }^{14}$ cadillac dijo

Carlos, es usted la persona que discutio ofendiendome en los comentarios de un articulo hace varios dias ????... respondi alla y espere su respuesta. no obstante le deseo que resuelva con su dentadura. 4 SEPTIEMBRE 2015 A LAS 14:06 / RESPONDER

Fonte: Captura de tela da conversação no fórum (realizada em novembro de 2018).

Figura 4 - Interlocutores criam laços através de espaços nacionais de discussão online ${ }^{15}$ La mexicana dijo:

Este comentario es para Cadilac, no te acuerdas de mi, soy Nabey la Italiana del foro Invasor y Vanguardia, como estás

27 NOVIEMBRE 2015 A LAS 15:14 / RESPONDERh

Fonte: Captura de tela da conversação no fórum (realizada em novembro de 2018).

A relação do pseudônimo com o conteúdo de uma mensagem é apenas um tipo de estratégia comunicativa acionada pelos participantes na conversação. Existem outros casos em que os sujeitos criam um nome para indicar uma característica geral que os identifica como interlocutores no fórum, assumindo assim uma identidade discursiva mais ou menos fixa dentro daquele espaço. Nesse viés, encontramos alguns dos seguintes exemplos: @AFECTADO, @liberal97; @La indignada, @Inconforme, @Soñador, @Pensando entre todos; @la justiciera, @Insistente, @Libre pensador, @la irrenunciable, @Con criterio propio, @El Rebelde; @Proecupao, @Comentarista Censurado (GHD), @Cansado.

Todavia, a exigência por declarar um tipo de "moral" que legitime um posicionamento pode vir de indagações alheias, mas também do próprio

14 Comentário da conversação sobre a matéria "Cubanos en Costa Rica esperan por solución", publicada no site, em 23 de novembro de 2015.

${ }^{15}$ Comentário da conversação sobre a matéria "Cuba tiene como prioridad mejorar la salud del pueblo, editorial de Granma", publicada no site, em 4 de setembro de 2015. 
sujeito que sente a necessidade de se autoafirmar, como forma de validação de seus pontos de vista. Essa estratégia discursiva aparece tanto nas narrativas e histórias dos sujeitos quanto no próprio nome usado para se identificar a partir de enunciar profissões, lugar de residência ou frases que revelam algum traço identitário relevante ligado à fala dos sujeitos. A seguir, apresentamos alguns exemplos que ilustram essa característica: @...desde Ecuador; @cubano de aquí y de allá, @Ing.; @profesorcienciasmedicas; @Medico, @Hipócrates; @ppprofesional, @joseluisestomatologo cfg; @ ando_apié.

Frases e adjetivos costumam ser a forma mais comum de se construírem esses apelidos, porém, destacamos como aspecto relevante as constantes referências à identidade cubana. Seja por cubanos que moram dentro do país ou por emigrados, há um interesse dos interlocutores por apelar ao imaginário nacional como forma de legitimar seus posicionamentos e seu lugar de fala na conversação. Assim, encontramos alguns exemplos como: @cuba, @Joven Cubano, @realista en cuba, @Cubano100\%, @Otrocubano, @DE CUBA CON O, @Ana la cubana, @negro prieto cubano, @viva Cuba, @AmoEstaIsla.

As opiniões defendidas por esses comentaristas variam do respaldo total às políticas do governo até reclamações ou duras críticas diante de problemas que Ihes afetam. Esse aspecto emerge como relevante no processo de politização da conversação, uma vez que gera enquadramentos questionadores do discurso oficial que estabelece equivalências entre Cuba como o país, a nação, e o processo político da Revolução Cubana e seus líderes. Os apelos à identidade nacional a partir de diferentes posicionamentos ideológicos ou pontos de vista sobre o que representa a Pátria para cada cubano estariam apontando deslocamentos nos limites do sistema político, reordenando o papel do cidadão como pertencente a essa terra.

Dessa forma, a ausência se configura como presença na esfera pública, fazendo com que o caráter discursivo do anonimato o afaste da 


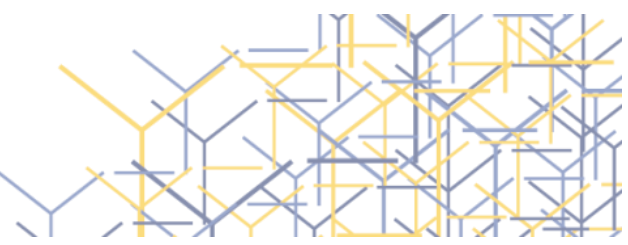

privacidade. Segundo Asenbaum (2018), o anonimato só pode proteger a identidade quando seu conteúdo comunicativo está no domínio da esfera pública. Para ele, o anonimato consiste tanto em um processo de criação de identidade, quanto na negação de uma identidade específica, "conferindo ao sujeito democrático um conjunto de liberdades positivas para agir, tendo-se em conta que a inclusão de uns implica exclusão e submissão de outros" (ASENBAUM, 2018, p. 460).

A partir destas análises, consideramos que em contextos de extrema vigilância e de diretrizes políticas totalitárias, o anonimato pode se tornar um recurso valioso para a construção discursiva e defesa de opiniões que desafiam os limites de atuação autônoma dos sujeitos. O indivíduo, assim, se desloca de sua realidade cotidiana, fora do espaço comunicativo do site, e passa a ocupar outro lugar na troca online. Um lugar que também é modelado intersubjetivamente, ao mesmo tempo em que traz as marcas da experiência singular que o legitima.

\section{Considerações finais}

O fato do fórum de comentários de Cubadebate pertencer à engrenagem comunicativa do governo, e ao mesmo tempo se abrir para discussões críticas, indica que existe uma multiplicidade de arenas de conversação cívica na sociedade cubana que não se apresentam como totalmente articuladas de antemão, mas que se tangenciam e se conectam em alguns momentos específicos, a partir de problemas e questões abordadas coletivamente. Espaços discursivos como esse são relevantes para se estudar os alicerces de um debate público online heterogêneo no contexto cubano.

A partir das análises apresentadas neste artigo, podemos concluir que o contexto não é apenas um pano de fundo no mapeamento de interações online e estudos de plataformas, mas pode se tornar um ator fundamental na emergência de dinâmicas político-discursivas veiculadas nesses espaços 
virtuais. É preciso levar em consideração também como a institucionalização da plataforma impacta no desenvolvimento da conversação; e como diretrizes editoriais e ideológicas que definem o meio colidem e se entrelaçam com as configurações tecnológicas desse ambiente; e como as possibilidades de anonimato que oferece o fórum são reapropriadas no processo enunciativo; e como a lógica do desenho digital é reelaborada pelos sujeitos que conversam.

Através do recurso do anonimato, vimos que os sujeitos podem ser capazes de se apropriar criativamente dos espaços comunicativos online, aproveitando brechas, resignificando funções comunicativas e reinventando as lógicas que Ihes são impostas pelas plataformas; em meio à construção relacional e comunicacional do anonimato como dimensão identitária. Assim, a dimensão política dessas práticas comunicativas emerge não apenas pelas capacidades do indivíduo ou pela garantia de condições democráticas prévias, mas enquanto são reinventadas as normas que definem uma determinada ordem política e discursiva.

Entretanto, essa condição não se restringe apenas às habilidades inventivas e de resistência apresentadas pelos interlocutores: ela abrange o processo reflexivo de entendimento e compreensão das desigualdades, assimetrias, injustiças e desequilíbrios que caracterizam a forma controlada de participação às discussões coletivas. Cubadebate não é um espaço livre para a promoção da democracia, mas um espaço vigiado de produção de opiniões e de uma semântica "autorizada" que passa a ter seus impactos nos entendimentos coletivos que guiam as ações e orientam os fazeres de vários cubanos e cubanas. São esses os cidadãos que recorrem ao meio e (II às suas práticas enunciativas para tomarem decisões e planejarem sua agência em um contexto marcado pela precariedade e pela forte intervenção do Estado na vida cotidiana dos cubanos que vivem na ilha ou fora dela.

Se bem o anonimato pode responder a fins de desqualificação contra os parceiros de interação, podemos ver como as estratégias de usos devem 
ser compreendidas em meio às características dos ambientes e contextos estudados. Essa é uma abordagem que deve ser considerada nos estudos sobre o impacto das TIC - Tecnologias da informação e comunicação nos processos comunicativos e sua dimensão política. Nesta pesquisa, observamos como o anonimato pode ser uma ponte entre a experiência cotidiana dos sujeitos e sua presença online como interlocutores, resignificando e transformando sua capacidade de agência em meio às restrições e limitações de acesso e participação dos cubanos nos espaços públicos de comunicação e nos mecanismos políticos do país.

Nesse sentido, constatamos que o recurso do anonimato presente nessas conversações e as apropriações que propicia pode constituir uma ponte entre a vida cotidiana na experiência coletiva dos cubanos e sua presença online, tecendo linhas de força e tensionando discursos hegemônicos que permeiam um espaço de visibilidade ampliada.

\section{Referências}

AJA, Antonio D. [et al.]. La migración internacional de cubanos. Escenarios actuales. Cuban international migration: current scenarios. Novedades en Población, Havana, v. 13, n. 26, p. 40-57, jul./dez. 2017.

ASENBAUM, Hans. Anonymity and Democracy: absence as presence in the public sphere, American Political Science Review, Cambridge, v. 112, n. 3, p. 459-472, 2018. Disponível em:

https://www.cambridge.org/core/journals/american-political-sciencereview/article/anonymity-and-democracy-absence-as-presence-in-thepublic-sphere/7D914F6529697778EB3D35C3C22065AE. Acesso em: 20 set. 2019.

BATHRICK, David. The Powers of Speech: The Politics of Culture in the GDR.

Lincoln: University of Nebraska Press, 1995.

BERG, Janne. The impact of anonymity and issue controversiality on the quality of online discussion. Journal of Information Technology \& Politics, v. 13, n. 1, p. 37-51, 2016. 


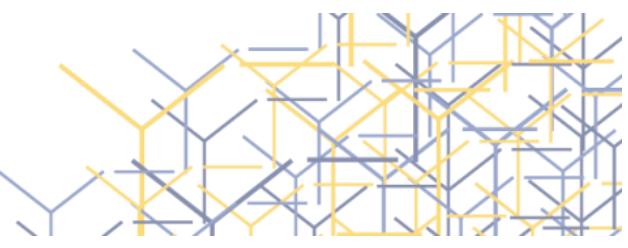

BUCHER, Taina; HELMOND, Anne. The Affordances of Social Media Platforms. In: BURGESS, Jean [et al.]. The SAGE Handbook of Social Media. London and New York: SAGE Publications Ltd, 2017.

BUENO, Thaísa. Para que servem os comentários de leitores na internet? Estudo sobre a utilidade da ferramenta nos sites de notícias a partir da estrutura do dispositivo e do modo de apropriação do internauta e do veículo. 2015. 265 f. Tese (Doutorado em Comunicação Social) Programa de Pós Graduação em Comunicação Social, Pontifícia Universidade Católica do Rio Grande do Sul,Porto Alegre, 2015.

COE, Kevin; KENSKI, Kate; RAINS, Stephen A. Online and Uncivil? Patterns and Determinants of Incivility in Newspaper Website Comments. Journal of Communication, v. 64, p. 658-679, 2014.

D'ANDRÉA, Carlos F. d'B. Cartografando controvérsias com as plataformas digitais: apontamentos teórico-metodológicos. Galáxia, São Paulo, n. 38, p. 28-39, mai./ago. 2018. Disponível em:

http://www.scielo.br/pdf/gal/n38/1519-311X-gal-38-0028.pdf.

Acesso em: 15 set. 2019.

FREELON, Deen G. Analyzing online political discussion using three models of democratic communication. New Media \& Society, v. 12, n. 7, p. 1172-1190, 2010. Disponível em:

https://journals.sagepub.com/doi/abs/10.1177/1461444809357927.

Acesso em: 13 ago. 2019.

GRAHAM, Todd; WRIGHT, Scott. A tale of two stories from "Below the Line" comment fields at the Guardian. The International Journal of Press/Politics, v. 20, n. 3, p. 317-338, 2015. Disponível em: https://journals.sagepub.com/doi/abs/10.1177/1940161215581926. Acesso em: 13 ago. 2019.

GUANCHE. Julio César. Estado, participación y representación políticas en Cuba: diseño institucional y práctica política tras la reforma constitucional de 1992. La Habana: Ruth Casa Editorial, 2015.

HERRERA, Alexei Padilla. A mídia religiosa na esfera pública em

Cuba: o papel desempenhado pela revista Espacio Laical. 2016. $239 \mathrm{f}$. Dissertação (Mestrado em Comunicação Social) - Programa de Pósgraduação em Comunicação Social, Universidade Federal de Minas Gerais, Belo Horizonte, 2016.

INTER PRESS SERVICE EN CUBA. Lo que no dicen las estadísticas sobre Internet en Cuba. 22 mar. 2018. Disponível em: https://goo.gl/BD2Cbv. Acesso em: 02 dez. 2019. 
LINZ, Juan J. Del autoritarismo a la democracia. Estudios Públicos, n. 23, 1986.

Disponível em: https://goo.gl/Ud7TnV. Acesso em: 11 out. 2019.

MAIA, Rousiley C. M.; REZENDE, Thaiane A. S. Respect and disrespect in deliberation across the networked media environment: Examining multiple paths of political talk. Journal of Computer-Mediated Communication, v. 21 , n. 2, p. 121-139, 2016. Disponível em:

https://academic.oup.com/jcmc/article/21/2/121/4065365. Acesso em: 02 nov. 2019.

MINISTÉRIO DA INFORMÁTICA Y AS COMUNICAÇÕES. Resolução 127/2007. Disponível em: https://goo.gl/WTGzlY. Acesso em: $02 \mathrm{dez}$. 2019.

MUNGEAM, Frank; CRANDALL, Heather. Commenting on the news: How the degree of anonymity affects flaming online. Unpublished thesis, MA Program in Communication and Leadership Studies, Gonzaga University, 2011. Disponível em:

http://web02.gonzaga.edu/comltheses/proquestftp/Mungeam gonzaga 0 736M 10111.pdf. Acesso em: 02 out. 2019.

OFICINA NACIONAL DE ESTADÍSTICA E INFORMACIÓN. Anuario estadístico de Cuba. Capítulo 17: Tecnología de la información y las comunicaciones, 2017. Disponível em: https://goo.gl/kWXcf]. Acesso em: 13 out. 2019.

READER, Bill. Free Press vs. Free speech? The Rhetoric of "civility" in regard to Anonymous Online Comments. Journalism \& Mass

Communication Quarterly, v. 8, n. 3, p. 495-513, 2012. Disponível em: https://journals.sagepub.com/doi/abs/10.1177/1077699012447923.

Acesso em: 02 dez. 2019.

SAMPAIO, Rafael. C.; BARROS, Samuel, A. R. Can news sites stimulate online deliberation? A study of readers' comments posted on folha.com.

Brazilian Journalism Research, v. 8, n. 2, p.188-205, 2012. Disponível em:

<U https://bjr.sbpjor.org.br/bjr/article/view/474. Acesso em: 15 dez. 2019.

VAN DIJCK, José. The culture of connectivity: A critical history of social media. Oxford: University Press, 2013.

WELTEVREDE, Esther; BORRA, Erik. Platform affordances and data practices: The value of dispute on Wikipedia. Big Data \& Society, v. 3, n. 1, 2016. Disponível em: 
https://journals.sagepub.com/doi/full/10.1177/2053951716653418. Acesso em: 02 dez. 2019.

WITSCHGE, Tamara. Examining online public discourse in context: a mixed method approach. Javnost-the public, v. 15, n. 2, p.75-92, 2008. Disponível em:

https://www.rug. nl/research/portal/publications/examining-online-publicdiscourse-in-context(37e37a38-2491-427a-86d2-5c306f2a0754).html. Acesso em: 10 dez. 2019.

WRIGHT, Scott. The role of the moderator: Problems and possibilities for government-run online discussion forums. In: DAVIES, Todd; GANGADHARAN, Seeta Peña. Online deliberation: Design, research, and practice. Califórnia: CSLI Publications, 2009. p. 233-242.

WRIGHT, Scott; STREET, John. Democracy, deliberation and design: the case of online discussion forums. New Media \& Society, v. 9, n. 5, p. 849-869, 2007. 